\title{
REFLEXÃO SOBRE AS VICISS ITUDES DE MATEMÁTICOS EM PERÍODOS BÉLICOS: O CASO DE JOSÉ SEBAS TIÃo E SILVA
}

\author{
Cecília Costa \\ Universidade de Trás-os-Montes e Alto Douro - UTAD - Portugal \\ Centro de Investigação em Didática e Tecnologia na Formação de Formadores - CIDTFF
}

(aceito para publicação em novembro de 2017)

\begin{abstract}
Resumo
A reflexão histórica que apresentamos surgiu da leitura de duas cartas de Sebastião e Silva para Vicente Gonçalves, escritas em Roma, em agosto de 1945 e em março de 1946. Sebastião e Silva permaneceu nesta cidade, de 1943 a 1946, como bolseiro para desenvolver investigação com vista ao doutoramento. Período em que a Europa vivia a II Guerra Mundial. Não temos conhecimento de algum estudo que contextualize essa fase da vida deste Matemático no período bélico que se vivia. É, pois, o que fazemos neste artigo, partindo do testemunho na primeira pessoa de Sebastião e Silva sobre as vicissitudes vividas nessa altura.
\end{abstract}

Palavras-chave: Matemática, História, Biografia, Sebastião e Silva.

\section{[REFLEC TION ON MATHEMATICIANS' VIC ISSITUDES IN W AR PERIODS: THECASE OF JOSÉ SEBASTIÃO E SILVA]}

\begin{abstract}
The historical reflection we present comes from the reading of two letters from Sebastião e Silva to Vicente Gonçalves, written in Rome in August 1945 and March 1946. Sebastião e Silva remained in this town, from 1943 to 1946, as a fellow to develop research to do his PhD. Period in which Europe lived the Second World War. We are not aware of any study that contextualizes this phase of the life of this Mathematician during the war period. Therefore it is our goal in this paper starting from the testimony in the first person of Sebastião e Silva about the vicissitudes lived at that time.
\end{abstract}

RBHM, Vol. 17, no 33, p. 17-30, 2017 
Keywords: Mathematics, History, Biography, Sebastião e Silva.

\section{1 - Introdução}

A guerra é um tema recorrente na História da Humanidade e está tratada em múltiplos estudos com grande profundidade e segundo diversas perspetivas. A História da Matemática e dos Matemáticos não é exceção.

Existem estudos sobre matemáticos em tempo de guerra, em particular durante a II Guerra Mundial relatando as vicissitudes e, por vezes, atrocidades, por eles sofridas (HUCKLE, s/d). Normalmente trata-se de estudos históricos abrangentes e globais, no entanto, há já algum tempo que historiadores começam a dar voz às histórias a nível local e individual, as quais retratam a realidade passada segundo outros pontos de vista. Testemunhos orais, correspondência pessoal, fotografias, diários, entre outros, são fontes históricas que dão voz a um novo tipo de história.

O estudo que apresentamos enquadra-se neste grupo pois baseia-se em duas cartas de José Sebastião e Silva (1914-1972) para José Vicente Gonçalves (1896-1985) escritas em Roma em pleno conflito bélico mundial. Procuramos dar uma visão mais individualizada da vivência deste jovem matemático português num contexto conturbado de guerra. José Sebastião e Silva é reconhecido como um dos maiores matemáticos portugueses. Há vários estudos históricos sobre a sua vida e obra, mas ainda muito mais pode ser aprofundado e analisado segundo outros pontos de vista (COSTA \& TEIXEIRA, 2007). É no âmbito deste segundo as peto que pretendemos dar algum contributo.

Sebastião e Silva permaneceu em Roma, de fevereiro de 1943 a dezembro de 1946, como bolseiro do Instituto de Alta Cultura junto do Istituto Nazionale di Alta Matematica, para desenvolver a sua investigação com vista ao doutoramento (SILVA, 1948).

É conhecida a frase: “Até Agosto de 1944 a sua actividade foi fortemente afectada pelos acontecimentos bélicos, mas a partir dessa data poude trabalhar em condições relativamente normais" (SILVA, 1948, pp. 3-4). Frase que lemos e relemos em vários escritos sobre Sebastião e Silva e que, confessamos, não nos causou grande impacto (COSTA \& TEIXEIRA, 2007). No entanto, quando ao explorar o espólio de José Vicente Gonçalves, encontramos uma carta de Sebastião e Silva para aquele matemático, enviada de Roma, em agosto de 1945 e a lemos... Papel de carta fininho com mais de meio século, que tinha estado nas mãos destas duas grandes personalidades, e que agora se encontrava entre as nossas, causou-nos uma emoção inesperada.

As palavras escritas pelo punho de Sebastião e Silva "Como V. Ex. ${ }^{a}$ deve saber, a vida em Roma não tem corrido sempre plácida e uniforme." (SILVA, 1945) tiveram eco no modo como tínhamos pensado a estada de Sebastião e Silva em Roma. Assim procuramos olhar para esta fase de forma articulada entre o pessoal/individual, o micro, com foco em Sebastião e Silva e, o global, o macro, a II Guerra Mundial. Repare-se que a carta é escrita após o términus da guerra na Europa (datado de 7 de maio de 1945). A carta é de agosto, e 
nota-se que Sebastião e Silva retrata uma situação que sabe já estar ultrapassada. Tal perpassa toda a carta.

\section{2 - Contextualização}

Centramo-nos num intervalo temporal de quatro anos, com uma variação de três anos. Ou seja, o período, central, de 1943 a 1946 em que Sebastião e Silva esteve em Roma, pontualmente alargado até cerca de três anos antes, 1940, e três anos depois, 1949.

Neste espaço temporal, temos um Sebastião e Silva com idade entre os 28 e os 33 anos, solteiro, licenciado em Ciências Matemáticas há cerca de cinco anos e meio (julho de 1937), mas apenas contratado como docente $-2 .^{\circ}$ assistente da Faculdade de Ciências de Lisboa - há um ano, em fevereiro de 1942. Nos três anos antes de partir para Itália, já era bolseiro do Instituto para a Alta Cultura, e trabalhava no Centro de Estudos Matemáticos de Lis boa (SILVA, 1948).

A II Guerra Mundial eclodiu a 1 de setembro de 1939, com a invasão da Polónia pela Alemanha. Terminou a 2 de setembro de 1945 com a rendição do Japão, ou seja, o período de vida de Sebastião e Silva a que nos estamos a referir coincide como período da II Grande Guerra e do pós-guerra (cerca de 3 anos) (Figura 1).

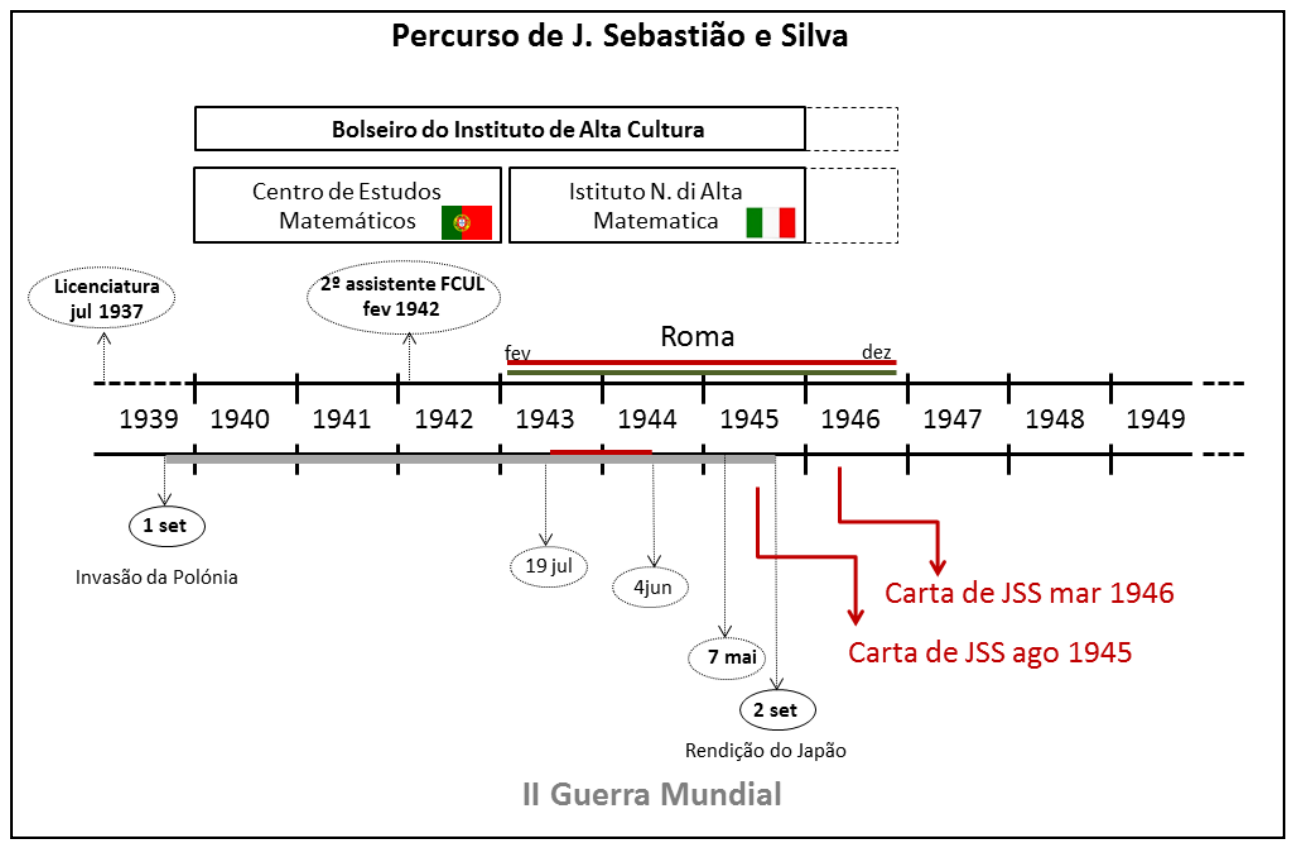

Figura 1 - Esquema síntese do período em análise 


\section{1 - A II Grande Guerra em Portugal}

Os anos de 1940 a 1942, em Portugal, ainda que marcados pelas vicissitudes, previstas e imprevistas, de tempos de guerra, não foram dramáticos. Salazar, ideologicamente simpatizante com o totalitarismo (nazi e italiano), mas aliado da Grã-Bretanha desde há muito e com interesse na manutenção dessa aliança, soube estabelecer e manter uma política de neutralidade em relação a este conflito (ROSAS, 1998). Fernando Rosas, sobre este momento histórico português afirma que:

"A política de neutralidade, definida em nota oficiosa logo a 1 de Setembro de 1939, imediatamente após o ataque alemão à Polónia, surgia, assim, como a forma de garantir os grandes objectivos estratégicos da política externa portuguesa (...) num contexto de inalterada fidelidade à aliança britânica.” (ROSAS, 1998, pp. 267-268).

Portanto, em Portugal continental, neste cantinho da península ibérica, particularidade geográfica que também pesou para este efeito, não se vivenciaram cenários de guerra, mas nem por isso a guerra deixou de invadir o dia-a-dia dos portugueses. Por todo o lado se sentia o ambiente bélico (ROSAS, 1998): nos racionamentos que dão origem a longas filas à porta dos estabelecimentos para compra de bens essenciais; nas conversas nos cafés, nos filmes e documentários sobre os acontecimentos da guerra; no corte da iluminação das cidades durante a noite e na colocação de tiras de papel (em xadrez) nos vidros das janelas das casas para evitar a localização aérea das zonas habitacionais; na escuta clandestina de emissoras de rádio estrangeiras na expectativa de saber notícias sobre a guerra.

Foi este ambiente que Sebastião e Silva deixou, para ir até à capital italiana, coma vontade de aprofundar os seus conhecimentos científicos e elaborar os estudos com vista ao doutoramento, no entanto o ambiente que encontrou era tudo menos propício ao estudo e reflexão.

\section{2 - A II Grande Guerra em Itália}

O envolvimento da Itália na II Grande Guerra foi muito diferente do de Portugal. A Itália fascista de Benito Mussolini teve participação ativa, ao lado da Alemanha. Começa por afirmar neutralidade em dezembro de 1939, mas logo em 1940, a 10 de junho, declara guerra à França e ao Reino Unido, a 4 de agosto invade e toma a capital da Somaliândia Britânica (protetorado britânico no norte de África), a 28 de outubro ataca a Grécia. Em junho de 1941, juntamente com a Roménia, declara guerra à União Soviética e em dezembro, agora com a Alemanha, declara guerra aos Estados Unidos (WILLIAMS, WALLER \& ROWETT, 1999).

Naturalmente, que face a isto, a Itália sofre também ataques em várias zonas do seu território, em particular, a 19 de julho de 1943, as tropas dos Aliados bombardeiam Roma (WILLIAMS et al, 1999). 
É esta a Itália que Sebastião e Silva encontra e é nesta Roma que se instala durante quatro anos.

\section{3 - Sebastião e Silva e o ambiente da II Grande Guerra em Itália}

Os relatos atrás referidos de modo quase enciclopédico do ambiente da II Grande Guerra e, os que se lhes seguiram, foram vividos intensamente por Sebastião e Silva e tocaram-nos mais, lidos na missiva escrita pelo seu próprio punho, do que nas obras sobre a história da II Guerra Mundial.

Sebastião e Silva escreve: "Em 19 de Julho de 43 deu-se o primeiro bombardeamento de Roma; uma semana depois a queda do fascismo; a 8 de Setembro o armistício e a defesa abortada de Roma.". Antes do que, a 3 de Setembro, Hitler ordena a invasão e o desarmamento do exército italiano, pelo que Roma é ocupada pelas tropas alemãs, como Sebastião e Silva tão bem descreve: "Entrou-se, então no período da ocupação alemã, que se prolongou até 4 de Junho de '44 [altura em que Roma é libertada pelos Aliados] - longo período durante o qual meia Roma viveu escondida e a actividade escolar foi praticamente nula."

Quatro meses e meio após Sebastião e Silva ter chegado a Roma, já nesse período em clima de guerra, segue-se um ano de guerra in loco, onde se tornou quase impossível estudar e investigar, únicas finalidades que levaram o jovem matemático a Itália.

A sua bolsa era para o Istituto Nazionale di Alta Matematica, instituição recente à data, pois foi fundada em 1939, por Francesco Severi. Matemático italiano nascido em Arezzo em 1897 e falecido em Roma em 1961 (BOMPIANI, 1962). É considerado um dos líderes da Escola Italiana de Geometria Algébrica, tendo deixado contribuições relevantes nessa área e na da teoria das funções com variáveis complexas (BOMPIANI, 1962). À data tinha cerca de 65 anos, e a apreciação, no âmbito do ambiente matemático italiano, que Sebastião e Silva faz dele é a seguinte: "Actualmente [agosto de 1945], em Itália domina a escola de Geometria algébrica, de que são autores principais Enriques, Castelnuovo e Severi - os dois primeiros já quase inactivos, pela idade. Eu, para a Geometria algébrica, não me sinto grandemente inclinado (...)". O Istituto Nazionale di Alta Matematica durante o período bélico mais atribulado em Roma esteve fechado (SILVA, 1945).

Sebastião e Silva também recorreu ao Istituto Nazionale per le Applicazioni del Calcolo, instituição fundada em 1927 por Mauro Picone (CIMMINO, 1978). Matemático italiano nascido em Palermo em 1885 e falecido em Roma em 1977, reconhecido pelo impulso que deu ao cálculo automático (CIMMINO, 1978). É também essa a opinião de Sebastião e Silva à data:

“(...) Picone que trabalha no mesmo campo [equações diferenciais], mas cujo mérito principal é o de ter criado o Istituto per le Applicazioni del

RBHM, Vol. 17, no 33, p. 17-30, 2017 
Calcolo, em que centenas de questões interessantes se apresentam anualmente, provenientes dos mais variados ramos da Ciência e da Técnica. A este instituto, que tanto prestigia a Matemática aos olhos do 'homem da rua', está destinado um papel muito importante na reconstrução da Itália." (SILVA, 1945).

Sebastião e Silva teve oportunidade de contactar com estes matemáticos.

\section{4 - Vicissitudes causadas pelo ambiente bélico}

As vicissitudes causadas a Sebastião e Silva e a alguns matemáticos italianos devido a este ambiente não vêm relatadas nas obras de história da II Grande Guerra, mas esta carta de Sebastião e Silva, de 1945, mostra bem as dificuldades diversas por que passaram.

Para além da anormalidade da vivência quotidiana de tempos de guerra, como por exemplo, a dificuldade em enviar correspondência para Portugal, o que para quem está fora constituiu um problema, outros tinham também peso relevante.

O facto de instituições fecharem durante esse período, como já referimos ter sido o caso do Istituto Nazionale di Alta Matematica, e também da Accademia dei Lincei, ou, na tentativa de protegerem o espólio, o guardarem em lugares seguros, como aconteceu com a biblioteca da faculdade da universidade de Roma "La Sapienza" (SILVA, 1945), impossibilitou o normal desenrolar dos trabalhos, em particular daqueles que são bas eados em pesquisa bibliográfica, como era o caso dos de Sebastião e Silva.

Durante cerca de um ano, o tal período em que "meia Roma viveu escondida", Sebastião e Silva diz que lhe "Foi[-me] então possível manter contactos unicamente com Fantappiè, que pôs à nossa disposição a sua biblioteca, porquanto aquela da Faculdade jazia no subterrâneo.".

Atitude louvável que Sebastião e Silva reconhece e agradece na explicação prévia existente na sua tese de doutoramento (SILVA, 1985). Já, a opinião de Sebastião e Silva sobre a qualidade científica de Fantappiè é nesta carta menos lisonjeira que nesse agradecimento. Repare-se nas suas palavras:

"Quanto a Fantappiè, a sua envergadura é modesta, quer como investigador, quer como professor. Na teoria dos funcionais a nalíticos há coisas interessantes, à mistura com muita confusão; nas aplicações, esta teoria pode geralmente ser substituída com vantagem pelo método Transformação de Laplace. Todavia, recebe-se a impressão de que, tendo iniciado as suas investigações ainda sob a influência de Volterra, de quem era assistente, o Fantappiè tenha sofrido uma queda brusca nas 
suas qualidades de investigador, depois de ter conseguido resultados animadores. Além disso, prejudica-o muito a sua grossa ignorância a propósito do que se tem feito lá fora no campo da Topologia funcional, donde as deficiências dos fundamentos topológicos da teoria e a minha idea de estruturá-la sobre novas bases." (SILVA, 1945).

De referir que um dos objetivos da estada de Sebastião e Silva em Roma era o contacto com matemáticos italianos. $\mathrm{O}$ que com o cenário de guerra ficou condicionado. Ainda assim, Sebastião e Silva contactou com alguns matemáticos italianos sobre quem relata situações penosas vividas nessa altura devido à guerra. Sobre Enriques conta que:

"[Enriques] Está muito velho; durante o período nazi teve de refugiar-se em S. João de Latrão e a sua saúde ressentiu-se muito dos perigos por que passou; há pouco, foi receber a condecoração concedida a uma sua sobrinha, fuzilada em Florença como patriota. Com a entrada dos aliados foi-lhe prestada justiça apesar de ter já ultrapassado os 70 anos, ocupa de novo a cátedra de onde tinha sido afastado pela famosa lei racial." (SILVA, 1945).

Refere-se ainda a Volterra, como segue, "Todavia, entre os matemáticos hebreus perseguidos (Enriques, Castelnuovo, Levi-Civita, Fubini, Fano, G. Ascoli, Pincherle, etc.) o mais corajoso de todos foi Volterra, que, já em '35, pela sua atitude intransigente, tinha sido irradiado da Accademia dei Lincei."; bem como a Castelnuovo "Castelnuovo, apesar da sua avançada idade, conservou uma grande juventude mental; habita em frente da casa de Enriques, na qual também habitava Levi-Civita. Por mais, de 30 anos os três amigos viveram próximos." (SILVA, 1945).

Sebastião e Silva relata passo a passo o que foi fazendo durante este período, referindo os acontecimentos bélicos que foram ocorrendo e perturbando o seu trabalho:

"Em Janeiro [1944] comecei a elaborar o projecto da minha tese; porém, só a partir de Agosto [1944], quando a vida começou a reentrar na normalidade (a entrada dos aliados provocou uma espécie de caos durante dois meses), me foi possível trabalhar com plena eficiência; só então a biblioteca regressou à superfície, o que me permitiu iniciar as minhas colheitas bibliográficas. Todo o período até Dezembro [1944] consumi na redacção da tese e na colheita de dados bibliográficos numa actividade que se tornou febril, com a aproximação do termo do prazo exigido para o doutoramento." (SILVA, 1945).

RBHM, Vol. 17, no 33, p. 17-30, 2017 


\section{5 - O pós-guerra}

Como já referimos, esta carta (de agosto de 1945) foi escrita três meses após o términus da guerra na europa (7 de maio de 1945), o que de algum modo revela um Sebastião e Silva mais otimista, crente no restabelecimento da normalidade.

A frase "O Istituto de Alta Matematica de Roma reabriu em Janeiro, e eu comecei a frequentá-lo, na esperança de realizar um trabalho de Análise Funcional, que reflectisse a influência da escola italiana." (SILVA, 1945) é exemplo disso. Porém, uma outra carta de Sebastião e Silva para Vicente Gonçalves, existente no espólio deste, também enviada de Roma, mas cerca de meio ano mais tarde, a 28 de março de 1946 (SILVA, 1946a), mostra que a normalidade não foi reestabelecida assim tão facilmente.

Repare-se nas palavras bem mais desanimadas de Sebastião e Silva, ainda que com uma pontinha de refinado humor (que tanto quanto sabemos era uma das suas características):

"Mas a fortuna não está decididamente ao meu lado. A Accademia dei Lincei reabriu, efectivamente, em meados de Janeiro mas, logo em seguida, a sua actividade foi suspensa, pela razão de que um dos seus actuais dirigentes - um arqueólogo octogenário - está doente, e não consente que se faça a abertura solene da Accademia sem a sua augusta presença - o que, atendendo à morosidade da doença, leva muitas pessoas a desejar, pouco cristãmente, que o senhor se decida quanto antes a morrer. Bizarrias desta Itália, ainda um pouco destrambelhada, do post-guerra!"' (SILVA, 1946a).

Também aqui, uma observação que de algum modo traduz a imagem que Sebastião e Silva tinha da Itália daqueles tempos.

O tempo previsto da bolsa do Instituto de Alta Cultura era de cerca de 3 anos, como se depreende das palavras de Sebastião e Silva, na carta de março de 1946, "Ano e meio - cêrca de metade do inteiro período - foi para mim quási completamente inutilizado pelos acontecimentos bélicos." (SILVA, 1946a).

Ultrapassado o prazo da bolsa sem os resultados esperados atingidos - ainda que devido à instabilidade e limitações do período de guerra - implicou o corte da bolsa do Instituto de Alta Cultura. A situação era delicada e Sebastião e Silva sabia e ressentia-se disso, como denotam as palavras enviadas a Vicente Gonçalves:

“As razões de tal demora [na resposta à missiva] já o Snr. Doutor, em parte, as deve ter compreendido: os muitos afazeres e a intranquilidade de espírito de quem, a estas horas, já devia estar em Lisboa, e todavia se vê obrigado a conservar-se ainda em Roma, contra a declarada vontade dos superiores." (SILVA, 1946a). 
As dificuldades de Sebastião e Silva nesta fase do pós-guerra não se limitaram a aspetos ligados às atividades académicas. A tentativa de prolongar a sua permanência em Roma para terminar os trabalhos de investigação que tinha em mãos, sem a bolsa e com as alterações da situação económica em itália do pós-guerra agravaram consideravelmente a vida a Sebastião e Silva, o que ele revela do seguinte modo:

"Entretanto o tempo passa, e não é em vão: no princípio dêste mês o I. A. C. cortou-me os viveres e eu vejo-me na dura necessidade de apertar, cada vez mais, $\underline{\underline{c}} \underline{\text { cinto }}$. A vida aqui tornou-se diabolicamente cara, e as vantagens do câmbio passaram há muito ao domínio das coisas legendárias. Vai-me ser preciso um bocadinho de coragem, nesta difícil conjuntura." (sublinhado no original) (SILVA, 1946a).

Talvez este desabafo escondesse um singelo pedido de ajuda, pois ao mesmo segue-se a pergunta: "Será possível que o I. A. C. me retire completamente o seu apoio?" (SILVA, 1946a).

Não temos dados para responder a nenhuma das duas questões anteriores, nem se o Instituto para a Alta Cultura manteve o apoio, nem se Vicente Gonçalves teve alguma influência nisso, mas o facto é que à data desta carta (28 de março de 1946) Sebastião e Silva previa regressar a Lisboa antes de junho ou julho (pouco legível no original) e só regressou em dezembro, conseguindo estender a sua estada em Roma cerca de meio ano. Conseguindo, pelo menos em parte, concretizar o seu desejo, veementemente expresso nas palavras seguintes:

"Ninguémpode dizer que eu tenha sido excessivamente venturoso, quanto às circunstâncias que acompanharam esta minha permanência fora do País. Outros têm sido, seguramente, mais fortunados do que eu. Ano e meio - cêrca de metade do inteiro período - foi para mim quási completamente inutilizado pelos acontecimentos bélicos. Não é então humano este meu desejo de respirar por mais algum tempo o ar da liberdade - levando a bom termo os trabalhos que tenho entre mãos agora que a Itália já não é aquela inóspita barcaça, a desconjuntar-se no mais terrível temporal da História? Sim, eu creio que é humano e compreensível e justo. Apesar de tudo o mais: da necessidade do doutoramento, etc." (SILVA, 1946a).

Explicando o que pretende dizer ao usar o termo "liberdade":

De resto, liberdade, para mim, outra coisa não significa senão possibilidade de dedicar-me inteiramente, $\underline{\text { e }} \underline{\text { num }} \underline{\text { ambiente }} \underline{\text { adequado }}$ à actividade de investigacão. Nêste momento, estou-me ocupando de certos trabalhos a que atribuo muita importância e que, uma vez interrompidos, com o meu regresso, não sei se ou quando poderiam vir a ser retomados." (sublinhado no original) (SILVA, 1946a). 


\section{6 - Nem tudo foram espinhos...}

É sabido que os acontecimentos bélicos têm muitas consequências negativas graves, mas também são comuns transformações sociais e económicas significativas, bem como progresso em várias vertentes da sociedade, como por exemplo nas áreas científicas e tecnológicas (SILVA, J.C., 2014).

Apesar das dificuldades, instabilidade e intranquilidade vividas por Sebastião e Silva, durante o período em Roma, conseguiu atingir os objetivos que o levaram até lá. Contactou com vários matemáticos italianos que já fomos referindo, e, em particular, com Enriques e Severi, o que refere explicitamente “(...) tenho ido visitar frequentes vezes Enriques e Severi." (SILVA, 1945). Detalhando os temas que discutia, refere que

"Com o primeiro, tenho conversado muito sobre filosofia da matemática; êle interessa-se bastante pelo que se tem feito no campo da Lógica e das matemáticas abstractas, começando a referir-se a êste género de trabalhos com uma ponta de cepticismo e terminando por se entusiasmar." (SILVA, 1945).

Esse contacto verificou-se também na participação em cursos de conferências (COSTA \& TEIXEIRA, 2007). Como Sebastião e Silva refere, no seu curriculum vitae de 1948 (SILVA, 1948), pode assistir a cursos e conferências, designadamente a um curso de Fantappiè sobre equações diferenciais e sobre a sua teoria dos funcionais analíticos (já vimos o que Sebastião e Silva pensava sobre is so e que o levou à elaboração da sua tese de doutoramento), outro de Severi sobre geometria algébrica, e outro de Cesari sobre cálculo das variações.

A carta de agosto de 1945, permite afirmar que Sebastião e Silva também apresentou conferências, pelo menos num ciclo de conferências do Istituto Nazionale di Alta Matematica, onde apresentou alguns resultados da sua tese, como afirma, e que teve consequências no desenrolar da sua produção científica como veremos. Sebastião e Silva explica o que aconteceu, com detalhe: "Após as conferências, o Prof. Severi pediu-me que redigisse em italiano, sem demonstrações, uma nota relativa a esses resultados, a fim de a comunicar à Academia Pontificia." (SILVA, 1945). O que veio a acontecer na sessão da Accademia Nazionale dei Lincei de 15 de junho de 1946 (SILVA,1946c).

A necessidade de escrever tal nota provocou desenvolvimentos interessantes que Sebastião e Silva explica com detalhe:

"Sucedeu porém este facto: enquanto redigia a nota pedida, surgiram-me novas ideias, que comecei a desenvolver de modo que em pouco tempo, a minha Tese se encontrava nitidamente superada. Muitas das questões que, na Tese, eu apenas formulava, encontraram agora completa resposta; muitas demonstrações foram aperfeiçoadas e simplificadas; vários conceitos foram esclarecidos, submetidos a uma análise mais profunda. Em particular, resolvi o problema que consistia em, dado um 
grupo de transformações biunívocas de um conjunto em si mesmo, determinar a organização a introduzirnesse conjunto, para que o sistema obtido admita como grupo de automorfismos o grupo dado. É claro que, em casos particulares, o problema pode ser acrescido de novas condições: assim acontece com o problema de Wiener e com o problema que consiste em, dado um grupo de Lie, determinar a geometria caracterizada por esse grupo. Na Tese não chego a referir-me às ideias de Klein e Poincaré, relativos à classificação das geometrias mediante o conceito de grupo; fui dominado exclusivamente pela preocupação de generalizar a teoria de Galois, o que me levou a uma visão unilateral do assunto." (SILVA, 1945).

É conhecido que Sebastião e Silva, em Roma, fez não um, mas dois "doutoramentos" ... O trabalho de Sebastião e Silva intitulado "Para uma teoria geral dos homomorfismos" foi feito durante o período que esteve em Roma, como o próprio afirma na introdução do mesmo quando escreve: "Antes de terminar, devo pôr em relevo as dificuldades de várias ordens que acompanharam a elaboração desta tese, concebida e escrita em Roma nos anos 1943 e 1944." (SILVA, 1985, vol. I, p. 141).

Esta não foi a tese de doutoramento apresentada em Lisboa e só foi publicada postumamente aquando da publicação das "Obras de José Sebastião e Silva", em 1985. No preâmbulo do volume I desta compilação os responsáveis pela mesma, J. Campos Ferreira, J. Santos Guerreiro e J. Silva Oliveira, afirmam que “(...) Sebastião e Silva chegou a encarar a possibilidade de apresentá-lo em Lisboa como tese de doutoramento, mas, por razões conjunturais, acabou por afastar essa hipótese." (SILVA, 1985, vol. I, p. 3).

A tese de doutoramento apresentada em Lisboa, em 1948 e defendida em 1949, intitula-se "As funções analíticas e a análise funcional".

A carta de agosto de 1945 (SILVA, 1945) dá a conhecer detalhes do desenvolvimento destes (e de outros) trabalhos de investigação, como passamos a detalhar.

Como dissemos, durante o ano de 1944, Sebastião e Silva elaborou um trabalho ao qual se refere como "a minha Tese". O Istituto Nazionale di Alta Matematica reabriu em janeiro de 1945 e a partir daí Sebastião e Silva começou a frequentá-lo, segundo ele,

“(...) na esperança de realizar um trabalho de Análise Funcional, que reflectisse a influência da escola italiana. Foi então que tive a ideia de um estudo sobre a topologia do espaço funcional analítico, o que me conduziu a uma nova sistematização da teoria dos funcionais analíticos, em bases que me parecem mais seguras. Ainda não me foi possível levar a termo a redacção desse trabalho que, espero, será publicado em Itália." (SILVA, 1945).

Na carta de março de 1946, retoma este tema dizendo:

“(...) em Setembro [1945] eu tinha visto que, com a aplicação de conceitos e resultados expostos na minha tese, seria possível simplificar e

RBHM, Vol. 17, no 33, p. 17-30, 2017 
aperfeiçoar grandemente a teoria dos funcionais analíticos do Fantappiè. Até hoje, entre outras coisas, tendo explorado êsse campo em vários sentidos, e agora estou preparando uma nota definitiva que será apresentada à Accademia dei Lincei, e da qual desejaria conhecer, in $\underline{\text { loco }}$, as repercussões nêste ambiente." (sublinhado no original) (SILVA, 1946a).

Efetivamente, Sebastião e Silva ainda estava em Roma quando tal trabalho foi lido e aprovado na sessão da Academia de 16 de outubro de 1946.

Nestas considerações Sebastião e Silva parece estar a referir-se aos estudos que darão origem à memória "L' Analisi funzionale lineare nel campo delle funzioni analitiche" (SILVA, 1946c) que foi apresentada à Accademia Nazionale dei Lincei por Picone, acompanhada por um relatório deste e de Castelnuovo; e à segunda tese, a de doutoramento.

Para além das duas teses, existem ainda outros trabalhos que foram efetuados neste período em Roma, usufruindo das potencialidades das instituições já referidas, em particular do Istituto Nazionale per le Applicazioni del Calcolo. Referimo-nos a dois artigos que foram apresentados por Picone à Academia na sessão de 18 de abril de 1946 (SILVA,1946b, 1948).

Consideramos que estes artigos são resultado das considerações seguintes que Sebastião e Silva tece na carta de agosto de 1945:

"Há pouco tive a grande satisfação de ver um trabalho meu ("Sur une methode d' approximation semblable à celle de Gräffe") [de 1941] serviu de assunto para a tese di laurea de uma aluna de matemática que, trabalhando no Instituto de Cálculo sob orientação do Prof. Picone, analizou o método do ponto de vista prático, chegando à conclusão de que, em certos casos, é preferível ao método de Gräffe - sobretudo quando se trata de equações de grau elevado, de que seja preciso determinar todas as raízes, reais e complexas; caso que se apresenta muito frequentemente no Instituto, para resolver problemas de electrotécnica, e que produz sempre um certo pânico entre os calculadores... A Tese da referida aluna alcançou a mais alta classificação, com louvor." (sublinhado no original) (SILVA, 1945).

Anunciando ainda que pretende desenvolver mais este assunto: “(...) a propósito do método de Gräffe eu tenho criado ideas que não quero deixar de pôr em prática; estou por isso desejoso de permanecer mais algum tempo em Itália, para poder encontrar a colaboração de um calculador do I.C. (...)." (SILVA, 1945). O que se veio a realizar.

\section{7 - Épilogo}


É sabido que Sebastião e Silva regress ou a Portugal em dezembro de 1946, retomou o cargo de 2. ${ }^{\circ}$ assistente em abril de 1947 e concluiu o doutoramento em 1949 (COSTA \& TEIXEIRA, 2007).

Apesar de todas as vicissitudes por que passou durante o período em Roma, fruto do desenrolar da II Guerra Mundial, foi lá que nasceu o especialista em Análise Funcional com contributos relevantes para a evolução desta área no pós-guerra.

\section{Bibliografia}

BOMPIANI, Enrico. 1962. Necrologio di Francesco Severi. In: Bollettino dell'Unione Matematica Italiana, vol. 17, no 2. 243-246.

CIMMINO, Gianfranco. 1978. Necrologio di Mauro Picone. In: Bollettino dell'Unione Matematica Italiana, vol. 15-A, $\mathbf{n}^{0}$ 1. 261-277.

COSTA, Cecília, \& TEIXEIRA, Isabel. 2007. Sebastião e Silva revisitado: retalhos biográficos, científico e pedagógicos. In: Boletim da SPM, vol. 57. 33-47.

HUCKLE, Thomas, s/d. Mathematicians during the Third Reich and World War II. http://www5.in.tum.de/ huckle/mathwar.html, acedido em 24/04/2015 às 9:13.

ROSAS, Fernando, 1998. O Estado Novo (1926-1974). In: J. Mattoso (Dir.), História de Portugal (vol. 7). Lisboa: Editorial Estampa.

SILVA, Jaime Carvalho e. 2014. Como a Matemática ajudou os aliados a ganhar a II Guerra Mundial (1939-1945). Comunicação apresentada no âmbito das Tardes de Matemática, SPM-Centro, em Coimbra.

SILVA, José Sebastião e. (agosto, 1945). Carta para J. Vicente Gonçalves. Existente no Espólio de J. Vicente Gonçalves à guarda do Arquivo da Universidade de Coimbra. Coimbra. Portugal.

SILVA, José Sebastião e. (março, 1946a). Carta para J. Vicente Gonçalves. Existente no Espólio de J. Vicente Gonçalves à guarda do Arquivo da Universidade de Coimbra. Coimbra. Portugal.

SILVA, José Sebastião e. 1946b. Complementi al metodo di Graffe per la risoluzione algebriche (2 notas). In: Rendiconti dell'Accademia Nazionalle dei Lincei, série 8, vol. I. 369-382.

SILVA, José Sebastião e. 1946c. Sull' analisi funzionale nel campo delle funzioni analitiche. In: Rendiconti dell'Accademia Nazionalle dei Lincei, série 8, vol. I. 709-715.

SILVA, José Sebastião e. 1948. Curriculum vitae de José Sebastião e Silva. Lisboa: Biblioteca Nacional de Lisboa.

SILVA, José Sebastião e. 1985. Obras de José Sebastião e Silva. Lisboa: Instituto Nacional de Investigação Científica.

WILLIAMS, Neville, WALLER, Philip, \& ROWETT, J. (1999). Cronologia do Século XX (trad.). Lisboa: Círculo de Leitores. 


\section{Cecília Costa}

Departamento de Matemática da ECT - UTAD -

Quinta de Prados - Vila Real - Portugal

CIDTFF - Universidade de Aveiro - Portugal

E-mail: mcosta@utad.pt 